\title{
ETHICS EDUCATION IN THE FIRST YEAR: AN EXPERIMENT
}

\author{
STEPHEN MCG. BUNDY*
}

I

\section{INTRODUCTION}

This is an account of one law school's experiment with teaching the required professional responsibility course in the first year. From spring 1992 through spring 1994, the University of California at Berkeley's School of Law (Boalt Hall) taught a required two-unit ${ }^{1}$ course entitled Legal Profession to all firstyear students, using a uniform set of teaching materials prepared and revised with the generous support of the W.M. Keck Foundation.

During this experiment, the faculty members involved in the course developed a strong set of teaching materials, a strong commitment to teaching from those materials, and an unshakable conviction that the course could not be taught properly in less than three units. The majority of Boalt's faculty were unwilling to make three units available for legal ethics in the first year, but were prepared to do so in the second year. Accordingly, at the close of our experiment, the faculty voted to expand the course to three units and to move the course to the second year.

The first part of this article presents the history of our required professional responsibility course, explains why our faculty initially decided to move the required course to the first year, and describes some important related decisions that influenced the course's design and reception.

The next part of the article offers a history of the experiment, which describes the curriculum we assembled, how we taught it, how the students reacted (in a nutshell, not well), how we revised our curriculum and pedagogy in light of that reaction, how the course improved, and how, notwithstanding that improvement, we ultimately decided to move the course to the second year.

Copyright $\odot 1996$ by Law and Contemporary Problems

* Professor of Law, School of Law (Boalt Hall), University of California at Berkeley.

Many people at Boalt Hall and elsewhere participated in the design, teaching, and evaluation of the Legal Profession course, and all are responsible for whatever is good in what follows. For comments, I am grateful to Bob Berring, Ed Frueh, Henry Hecht, Herma Hill Kay, Tom Metzloff, Eleanor Swift, and David Wilkins. The views expressed and errors made in this piece, however, are mine.

1. In 1991, a two-unit course at Boalt Hall represented 30 instructor contact hours taken over a 15-week semester, and a three-unit course, 45 instructor contact hours. Since 1994, due to adjustments in our schedule, two units has represented 28 contact hours taken over a 14-week semester and three units has represented 42 contact hours. A typical first-year student takes 15 or 16 units each semester. A typical second- or third-year student takes 13 or 14 . 
The concluding section attempts to move beyond the gritty particulars of our experience and to draw some tentative conclusions with broader application. It argues that our experience is consistent with prior research finding that student resistance to required professional responsibility instruction is more a function of latent curricular messages than of the year in which the student takes the course. In our case, the latent message that proved most potent and enduring was that Legal Profession was the only two-unit required course in the first year. Our experience also suggests that, because an important latent curricular message in most law schools is that theoretical and empirical work is not "real law," there may be real tension between achieving greater acceptance of the course and exposing students to the best available thinking concerning the profession they are about to enter. Ironically, that tension may be stronger in the first year, when students are most focused on mastering conventional legal analysis.

Because of the confounding presence of these latent messages, our experiment cannot be regarded as a definitive test of the pedagogical effectiveness of first-year placement. Such a test would call for a course taught at the same scale, and in the same manner, as traditional first-year courses. The case for that sort of first-year legal ethics course, I argue, may be as strong as or stronger than that for the prominence now given to other courses in the traditional first-year curriculum.

\section{BACKGROUND}

In the spring of 1991, the faculty at Boalt Hall voted to institute a new twounit first-year course entitled Legal Profession. The two units needed to create the course were taken from the Contracts and Civil Procedure courses, each of which was reduced from six to five units. Upon motion of a Contracts professor, the faculty agreed to make Legal Profession subject to a sunset provision at the end of the second (later extended to the third) year in which the course was offered. Unless extended at that witching hour, the first-year placement of the course would cease and Contracts and Civil Procedure would revert to their original lengths.

The decision to create a required first-year course in professional ethics came against a background of mixed results with required ethics courses in the second and third year. Beginning in the early 1980s, Boalt Hall had decided to fulfill its obligation under American Bar Association ("ABA") Standard 302(a)(4) to provide "instruction in the duties and responsibilities of the legal profession" and in the profession's "history, goals and structure"2 by requiring each student to take a course of at least two units concerning those subject

2. AMERICAN BAR ASSOCIATION, STANDARdS FOR APPROVAL OF LAW SCHOOLS AND INTERPRETATIONS standard 302 (1973). 
matters during the student's second or third year of law school. The ethics course thus became the school's only required offering after the first year. In choosing this option, the faculty rejected the alternative of legal ethics instruction by the pervasive method ${ }^{3}$ both because we feared that instructors in mainstream courses would not make a sufficient commitment of classroom time and personal energy to ethics instruction, and because we had a cadre of teachers who were prepared to participate, at least occasionally, in offering a specialized course in the subject.

At the time we decided to require a stand-alone, specialized course, we also committed to offer at least four courses per year satisfying the requirement, and in a fair number of years we fulfilled that ambition. Most students fulfilled their requirement in two-unit offerings entitled Professional Responsibility. The format and content of those courses varied with the instructor. Some were quite innovative, ${ }^{4}$ but many relied heavily on parsing the various professional codes. In general, student reaction to those courses-as gauged by end-of-semester evaluations-was more negative than their reactions to other second- and thirdyear courses and to other required courses (all of which were taught in the first year). In consequence, although a number of instructors taught the course once or twice, few instructors welcomed or accepted a regular assignment to teach it.

Other courses satisfying the ethics requirement ranged more widely. For example, one course, entitled Business, Law, and Ethics, taught jointly by Robert Cole and faculty members from the Haas Business School, began with foundational works of modern ethical theory and applied those theories to problems of moral reasoning and deliberation shared by lawyers and other professional and managerial workers. When offered, the course drew between 20 and 30 percent of those students fulfilling their requirement.

From 1984 through 1991, slightly less than 10 percent of each graduating class fulfilled their professional responsibility obligation in an ambitious fourunit seminar entitled Lawyers and Clients. As originally conceived by its designers, Robert Post, Ed Rubin, and Henry Hecht, the class relied on several innovations to generate deeper engagement with professional ethics issues and, in particular, a better understanding of how professional norms and behavior are influenced by the social context of legal practice. ${ }^{5}$ First, the instructors made extensive use of theoretical and empirical scholarly works on both the legal profession and professionalism more generally. Second, they taught much of the

3. The pervasive approach to teaching ethics involves introducing ethical issues piecemeal, in different law school courses, by instructors who know the context well and who understand in detail how legal rules, institutional arrangements, and ethical obligations interact in that context.

4. For example, Professor (now Judge) John Noonan, drawing on the Aristotelian conception of the good life, and perhaps anticipating the vogue for narrative as legal methodology, taught a course largely through the use of narratives drawn from the lives of renowned lawyers like Thomas More, Louis Brandeis, Paul Cravath, and Abraham Lincoln.

5. In this regard, the course anticipated some important scholarly developments. See, e.g., David B. Wilkins, Who Should Regulate Lawyers, 105 HARV. L. REV. 799, 877 (1992) (stressing the importance of considering practice context for design of professional regulation). 
course through simulation and role-playing. Third, approximately half the twenty-four students in each seminar combined the course with a clinical outplacement. Clinical students were taught participant observation methodologies so that they could better integrate their classroom and clinical experiences. The placements were designed to capture a range of practice experiences and included work in plaintiffs' consumer law, large firm practice, a bank's in-house counsel, the public defender and prosecutor's offices, and regulatory agencies such as the EPA and the SEC. The reaction to Lawyers and Clients from the students enrolled (all of whom had elected to take four units of legal ethics, rather than just the required two) was considerably more positive than the reaction to the regular professional responsibility course; instructors were correspondingly more willing to teach it.

The faculty's decision to create the Legal Profession course and station it in the first year was the sole survivor of a larger effort to reform the first-year curriculum; the other elements died aborning in a two-day faculty retreat held in 1990. The broader effort was an attempt to break up the steady stream of appellate cases on private law topics to which first-years are exposed. Elements of the strategy included reducing coverage in some first-year courses (or deferring one or more of them to second year) and adding the required Legal Profession course and a menu of courses dealing with applications of selected social sciences and humanities to law (from which students would have been required to select one). That the Legal Profession course proposal survived the faculty skepticism that killed the other proposed reforms reflected the perceived severity of the problems with the required second-and third-year professional responsibility course.

The move to the first year was intended to address several concerns. Perhaps most important, we hoped that placing the required course in the first year would improve its reception with students, making it easier to teach and hence easier to staff. First-year students, we theorized, are generally more open, and less jaded, than their second- and third-year counterparts. ${ }^{6}$ In addition, we believed that the professional ethics course had suffered from being the only required course in second and third year, both because later placement signaled that the course was less important than other required courses and also because the requirement chafed more severely once students had a taste of freedom in course selection. Consistent with this analysis, professors observed that the most hostile student responses to the required course and the worst teaching experiences consistently occurred with second-semester, third-year students who had delayed the requirement until immediately before graduation.

6. This insight is obviously not new. One can find it in Karl Llewellyn's Bramble Bush, which first appeared in 1930. KARL N. LLEWELlyN, THE BRAMBLE BUSH: SOME LECTURES ON LAW AND ITS STUDY 134 (1930). More recently, systematic studies have documented the phenomenon of increasing student disengagement and lack of interest in the second and third year. See Ronald M. Pipkin, Legal Education: The Consumer's Perspective, 1976 AM. B. Found. RES. JouRnal 1161; Robert Stevens, Law Schools and Law Students, 59 VA. L. REV. 551 (1973). 
Finally, some of us also thought we had observed a hunger among first-year students to gain a better sense of the world of practice, and reasoned that an ethics course with a practical component might satisfy that need.

Improved student reception was not the only-or for some, even the primary-gain expected from placing the course in the first year. In the spring of 1991, the time of the decision to move the course to the first year, many faculty members were strongly influenced by the effect upon our students of the boom in large firm hiring. The boom had made large firm jobs accessible to an unprecedented number of our students, frequently at a very early stage of their law school careers. In many cases, students were starting work at large law firms in the summer after their first year, and some were accepting permanent offers after that summer. We worried that students were making such momentous choices so early in their professional education, without any developed sense of the range of available professional opportunities and practice settings. We hoped that offering an ethics course in the first year would make our job-seekers better consumers, while also helping to dramatize issues about the distribution of legal services and to keep alive for some students the possibility of alternate forms of practice, whether in smaller firms, in government, or in public interest practice.

For many faculty members, a major attraction of the proposed course was its undertaking to replicate on a wider scale some of the successful innovations of Lawyers and Clients. For a host of reasons, we could not link the basic required course to live client clinicals or externships, as Lawyers and Clients had. But we wanted to continue that course's focus on how the setting of practice shapes lawyer obligations and conduct, its successful use of role-playing and other simulations to encourage students to engage with the issues, and its extensive use of theoretical and empirical literature on professionalism and the profession. The latter feature in particular attracted faculty members who had unsuccessfully sought to reform the first-year curriculum by adding courses with social science and humanities perspectives, some of whom saw Legal Profession as an entering wedge to a more comprehensive rethinking of the first-year curriculum. To ensure that the benefits of these innovations were generally disseminated, the faculty members who planned to teach the course agreed to develop and utilize a common set of teaching materials, from which all sections of the course would be taught.

We recognized that there were risks associated with our chosen approach. First, most prospective teachers of the course believed that the importance of the subject matter warranted allocating three units (forty-five classroom hours) to the course, and that a longer course would be more interesting and more likely to be taken seriously. But the majority of the faculty were not prepared

7. $C f$. Robert V. Stover, Making It and Breaking It: The Fate of Public InTerest COMMITMENT DURING LAW SCHOOL 115-20 (Howard S. Erlanger ed., 1989) (urging law schools to use the professional ethics course as part of a strategy to support public interest commitment against market forces). 
to give up more than two units of the first-year curriculum to an ethics course. A second risk was that first-year students would have little, if any, experience of law practice to draw upon in interpreting the material. We therefore seriously considered placing the course in the second year, where three units could be had and the students would be more experienced than first-years but not quite as "burnt-out" as third-years. We ultimately decided, however, that the potential advantages of first-year placement were substantial enough to warrant these risks.

After the faculty had decided to offer the first-year course, the Keck Foundation made a substantial grant to Boalt Hall to support the development of materials for legal ethics education. A portion of that grant was earmarked to support the development of materials for a first-year course. Among other things, that funding allowed us to devote additional faculty time to the development of the materials and to call on several expert visitors for advice and assistance in teaching the course. Another portion of the grant went to support other Boalt faculty in developing "plug-in" professional ethics modules for upperlevel courses. Although the faculty's vote to experiment with the firstyear course was made without regard to the possibility of foundation support, there is no question that the Keck Foundation's generous and patient support played an instrumental role in constructing a community of concerned scholars and teachers and creating a workable set of teaching materials.

\section{III}

\section{OUR EXPERIENCE WITH THE COURSE}

Over the next three years, Boalt Hall's faculty made a major commitment to the first-year course. Six faculty members taught Legal Profession one or more times, each time teaching from the same materials as their colleagues. ${ }^{8}$ Those six were joined in teaching the materials by two visiting professors ${ }^{9}$ and in revising the teaching materials by three visiting advisers and an experienced clinical teacher. ${ }^{10}$ The common materials and pedagogical strategy for the course were the product of extensive discussions and a level of collaborative effort unique for our faculty. We followed up each iteration of the course with detailed evaluations. In addition to our normal surveys of teaching effectiveness, we prepared a separate survey aimed at identifying how well students thought the course had achieved the pedagogical aims that had guided our design of the curriculum. Those aims included a better understanding of the adversary system, of the lawyer's role morality, and of the relationship between the student's own values and those espoused by the profession. We also

8. Those faculty members were Robert Berring, Stephen Bundy, Robert Post, Ed Rubin, Marjorie Shultz, and Eleanor Swift.

9. The two visiting professors were John Leubsdorf of Rutgers-Newark and John Adler of the University of San Francisco.

10. The four advisers were Leubsdorf, Deborah Rhode of Stanford, Marc Galanter of Wisconsin, and Henry Hecht, a lecturer at Boalt with a strong background in the use of simulations in teaching. 
conducted a series of small focus group interviews in which we debriefed students about their course experiences.

Our initial collaborative effort at a common curriculum drew heavily on the Lawyers and Clients seminar, particularly its emphasis on generous excerpts from classic scholarly texts on the adversary system and the legal profession. Thus, our initial syllabus featured, among others, Lon Fuller on the justifications for the adversary system, ${ }^{11}$ Malcolm Feeley and Robert Kagan on the political theory of adversarial legalism, ${ }^{12}$ Douglas Rosenthal on models of the lawyerclient relationship, ${ }^{13}$ David Luban on ethical frameworks for evaluation of negotiation outcomes, ${ }^{14}$ and W. Richard Scott on conflicts between professional and bureaucratic modes of organization. ${ }^{15}$ Because of our enthusiasm for these works and our desire to give students a real sense of their messages, the articles were often presented in substantially complete form, without extensive editing. We also drew initially on simulations developed for Legal Profession, including a well-worn negotiation simulation and a simulation of a large firm's decision to raise its starting salaries. ${ }^{16}$

In its initial iteration, the course fell well short of our aims. Student reaction was strongly negative, as reflected in evaluations both of instructors' effectiveness and of the course's success in achieving its pedagogical goals. This negative reaction had a number of components. First, the effort to squeeze the course into two units in the second semester of first year hurt its effectiveness, because students perceived it both as the only two-unit required course and as the "extra" course in the already crowded second-semester curriculum. Second, our hypothesis that first-year students would prove markedly more open to ethics education was too optimistic. As had been the case with our former offerings, a substantial number of first-year students continued to object to the study of legal ethics as patronizing, preachy, irrelevant, or intellectually soft. Our extensive initial use of theoretical and empirical materials from the cognate social sciences and humanities contributed to student dissatisfaction. In their course evaluations, students objected to such materials as "long," "boring," "irrelevant," "pompous," or, worst of all, "academic." Third, as often happens, the initial version of the teaching materials was too long and insufficiently edited.

11. Lon L. Fuller \& John D. Randall, Professional Responsibility: Report of the Joint Conference, 44 A.B.A. J. 1159 (1958).

12. Malcolm Feeley, The Adversary System, in 2 ENCYCLOPEDIA OF THE AMERICAN JUDICIAL SYSTEM: STUDIES OF THE PRINCIPAL INSTITUTIONS AND PROCESSES OF LAW 753-66 (1987); Robert A. Kagan, Adversarial Legalism and American Government, 10 J. POL'Y ANALYSIS \& MGMT 369, 371-79 (1991).

13. Douglas E. Rosenthal, Lawyer and Client: Who's in Charge? (1974).

14. David Luban, Bargaining and Compromise: Recent Work on Negotiation and Informal Justice, 14 PhIL. \& PuB. AfF. 397 (1985).

15. W. Richard Scott, Professionals in Bureaucracies: Areas of Conflict, in Professionalization 265 (H.M. Vollmer \& D.L. Mills eds., 1966).

16. The latter simulation was based on prior work by Michael Kelly of Maryland. See Michael Kelly, Mulroney Moreland and Fox Analyze the Doctrine of Cravatheat Emptor (undated xerograph). 
Nonetheless, it was apparent that the materials had promise. In particular, the use of simulations was an important strength. In the first year we taught the course, we developed two simulations dealing with lawyers in counseling and negotiation roles. These simulations were effective teaching tools, were well received by students, and have been adopted elsewhere. ${ }^{17}$

In response to these initial reactions, we did a wholesale revision of the course materials in both the second and the third year that the course was offered. We added problems drawn from practice and role-plays involving legislative and large firm settings. We reduced the length of the materials, while at the same time giving more prominence to doctrine and less to theoretical and empirical materials. This last shift was painful, because exposing our students to theoretical and empirical social science materials had been a principal objective of the course. But we knew we had to cut, and given the negative student reaction to its use, the academic literature seemed a good place to start. As we considered the question, we received conflicting advice from our outside advisers, with a social scientist arguing that we should increase the use of social science materials, a leading casebook author advising that extensive use of the social science materials would severely hinder the adoption of the course materials at other schools, and a reporter for the Restatement of Law Governing Lawyers arguing that the course was insufficiently doctrinal. Some of those who worked on the materials still believe that the decision to shift coverage in this fashion was a mistake.

Another major revision involved the steps that Professors Marjorie Shultz and Eleanor Swift, two of our most gifted and engaged instructors, took to improve the reception of the course, as taught in larger sections of sixty or ninety students. The strategies used by each professor had common structural elements: creating smaller ad hoc working and discussion groups within the class; requiring students to prepare more individual and group written exercises; and providing more feedback on the student output from those exercises. In

17. The first simulation, broadly modeled on a classic problem in legal ethics, involved counseling a client with a technical statute of limitations defense to an otherwise legally and morally compelling claim for breach of contract. Students were assigned to play the roles of both lawyer and client. Apart from the core problem of counseling ethics, the factual situation was written to highlight other normative problems central to the course, including the ethical responsibilities of law firm associates and of lawyers counseling organizational clients. This simulation has since been used both as part of Stanford Law School's Introduction to Legal Ethics program and at the University of San Francisco.

The second simulation was a reworking of the Valdez v. Ace Auto Repair negotiation, originally drafted by Steve Pepe when he was at the University of Michigan and elaborated by, among others, Gary Bellow and Bea Moulton. The Valdez simulation places students in the role of lawyers for the plaintiff and defendant seeking to settle a wrongful death claim. As traditionally presented, the hypothetical raises issues about candor in negotiation, the use and abuse of strong bargaining positions, and the line between legitimate predictions and illegitimate threats. Traditionally, those issues were raised almost exclusively for the defendant's lawyer, with plaintiff's lawyer playing the role of a patsy. Our principal contribution was to balance out the ethical freighting of the exercise by creating some candor and disclosure issues for the plaintiff's counsel as well. As revised, the exercise is now featured in the teacher's edition of Rhode and Luban's second edition of Legal Ethics. DEBORAH L. RHODE \& David Luban, Legal ETHICs (2d ed. 1995). 
one section, these strategies were supplemented by efforts to increase the frequency and intensity of student engagement by linking ethics issues with training in critical professional skills. This clinical strategy expanded the number of role-play exercises in the course and linked those role-plays to the development of interviewing, counseling, and negotiation skills. Students received additional readings and supplemental classroom lectures that focused solely on the skills component of the exercises. One cost of these steps to improve student engagement with the course was the extraordinary demand, in terms of time and energy, that it placed on the large section instructors. The other cost was the effective loss of uniformity in curriculum and approach, as each instructor made deletions, additions, and substitutions in an effort to make the material work more effectively with his or her teaching style.

Our refinements to the course resulted in a significant improvement in student reactions. Teacher effectiveness ratings rose significantly. More importantly, there was a dramatic and favorable change in how students evaluated our success in achieving the pedagogical goals of the course, an improvement that was strongest in courses where innovative strategies had been used. By spring 1994, students rated the course materials and the educational value of the course significantly higher, along a variety of measures, than in spring 1992, when the course was first offered.

Nonetheless, the course remained relatively unpopular and difficult to teach, especially in large sections. ${ }^{18}$ In each year that we offered the course, the instructors' ratings for the course were significantly below those for other large first-year courses, despite the fact that the course instructors included several of Boalt Hall's best regarded teachers. ${ }^{19}$ And in large classes where instructors failed to make special efforts like those of Professors Shultz and Swift, the results were sometimes as bad as the worst outcomes of the old regime.

\section{IV}

\section{The Decision to Move THE Course to The SECOND YeAR}

When it came time to take stock of the course, those who had been most involved recommended to the faculty that the course be expanded to three units, that students be required to take the course in their second year, and that the policy of uniform course materials be abandoned.

The only action on which there was strong consensus was expanding the course to three units. Those who had designed and taught the materials believed that the two-unit required course had been intolerably rushed and truncated, that the importance of the course and tremendous growth in the volume and complexity of the relevant law and academic literature fully warranted a required three-unit course, and that limiting the course to two units

18. As one student put it, "[i]t's not easy to discuss Durkheim with 100 of your closest friends."

19. In addition, every instructor in the Legal Profession course had instructor ratings significantly below those which they received in other courses that they taught over the same time span. 
had been an important reason why many students had viewed it as an "add-on" or academic stepchild. ${ }^{20}$

The decision to expand to three units was in turn decisive of the issue of first-year placement. It had been a struggle to pry loose two units from Contracts and Civil Procedure: There was no support for further shrinking another first-year course, and there was considerable concern that even the twounit course had badly overcrowded the first-year spring. If the course were to be taught in three units, it had to be moved out of the first year.

Would we have kept the course in the first year had space been available for a three-unit course? Certainly some faculty members would have strongly recommended keeping the course in the first year, and one or two might even have advocated moving it to the first semester of the first year. But all recognized that the case for leaving the course in first year was less promising than it had appeared in 1991. Our 1991 view of how first-year students would respond to the course had been naive. Our experience suggested that some level of resistance to a required course on professional issues may be inevitable. For some first-years, that resistance is tempered by their openness to new experiences and their eagerness to understand their metamorphosis into a professional. For others, though, such inquiries trigger resistance. Such students may benefit from later exposure after practice experience generates greater awareness of the real significance of ethical issues. ${ }^{21}$

External events also eroded some faculty members' enthusiasm for first-year placement. Shortly after we moved the course to the first year, the large law firm boom ceased, and over the following two years it became clear that law firm hiring was unlikely to return to the superheated days of the late 1980 s. Large law firm opportunities for our first-year students largely dried up and those for our second- and third-year students contracted significantly. As students' career trajectories resumed a more traditional shape, the need to provide an early exposure to a broader range of practice settings and ethical issues came to seem less urgent.

Given the change in the hiring market, the recognized disadvantages of firstyear placement again loomed larger, including notably the students' near total lack of practice experience. In addition, their lack of exposure to relevant advanced courses, such as Criminal Procedure, Corporations, Tax, and Environ-

20. For a similar analysis, see Ronald M. Pipkin, Law School Instruction in Professional Responsibility: A Curricular Paradox, 1979 AM. B. FOUND. RES. J. 247, 252 (noting that the number of units allocated may be a cue to the "latent hierarchy" of law school courses, with fewer units indicating a lower hierarchical status).

21. There is, of course, some support for the view that practice experience leaves students doubting the significance of ethical norms. See, e.g., Lawrence K. Hellman, The Effects of Law Office Work on the Formation of Law Students' Professional Values: Observation, Explanation, Optimization, 4 GEO. J. LEGAL ETHICS 537 (1991). It is striking, however, that many of the student interns in Hellman's sample, drawn from a single law school, worked in smaller personal injury and workers' compensation firms, a practice arena that may be unrepresentative. Id. at 557-63. My own observation is that work experience across a broader range of practice settings tends to give students and recent graduates a stronger sense of the salience of ethical concerns and of the real consequences of ethical missteps. 
mental Law, made it more difficult to teach important and conceptually demanding topics, such as compliance counseling, opinion letters, client perjury, and representation of corporations and other organizations.

The decision to move the course to the second year strongly influenced the difficult decision to abandon the commitment to teaching all sections of the course with the same materials. Much collective effort had been invested in devising and improving the course materials, and most of the Boalt Hall faculty members who planned to keep teaching in the field intended to continue using those materials. However, there were both pedagogical and practical advantages in restoring the potential for diversity. In our efforts to make the course more effective, each instructor had developed a set of topics that she viewed as more important and a set of strategies that she viewed as pedagogically effective. Thus, many of us felt it would be a step backward to return to a uniform approach.

It also seemed possible that the students might benefit from a range of approaches. Students who resisted ethics education because it was not "law" could be taught a course stressing the complex legal issues and demanding judgments that increasingly typify professional regulation. Students who wanted to address issues of personal identity, moral decisionmaking, and the professional role might well be reached by a different course. And the handful of students who wanted a richer exposure to theoretical and empirical perspectives could be reached by still a third course.

The potential for variety seemed necessary to recruit teachers, as well. Because of the high degree of personal commitment required to overcome student resistance and teach the course effectively, we wanted to allow new instructors from our own faculty to pursue distinct personal approaches. Moreover, we knew that given the competing demands on our faculty resources, we would sometimes have to call on visiting professors to teach the course, and felt we might have difficulty recruiting them if they had to alter their own approaches to conform to ours.

\section{REFLECTIONS AND LESSONS}

Our experience reflects themes familiar to American legal education: strong student resistance to required legal ethics education; the difficulty of supporting an institutional commitment to required legal ethics education for all graduates in an era of constrained resources; and the difficulty of major curricular reform, especially in the first-year curriculum. What I notice first, however, is how much of our decisionmaking was driven by the particular practical constraints of our situation and our institutional history. Certainly neither those advising the faculty nor the faculty itself had a worked-out theory of professional ethics education. Our horizons were largely limited by what had gone before and by the faculty's limited interest in reforming the first year. Nor did we have first- 
class data supporting our decisions. ${ }^{22}$ Instead, we relied on intuitions about the dynamics of first-year and upperlevel education and expectations about the job market for our students that proved unfounded.

I do not note the relatively unsystematic character of our approach in a critical spirit, ${ }^{23}$ but rather because I think it is typical of how professional responsibility instruction has evolved at many schools-incrementally, in accord with faculty energies and interests, other perceived curricular needs, and intuitive experiential judgments of teachers in the field.

Despite these peculiar local elements, the student response to our course is consistent with earlier research findings, notably Ronald Pipkin's excellent study of student resistance to professional ethics education. ${ }^{24}$ Pipkin's principal finding was that such resistance is less a result of the student's year in school than of what he calls "latent" curricular messages, including the number of units assigned to the course and whether the course is taught by the traditional Socratic method or as a discussion course. One implication of Pipkin's findings is that, in order to be accepted, a legal ethics course ought to become as much like a traditional law course as possible, increasing the number of units, stressing law over theoretical, empirical, or clinical approaches, and preferring Socratic interrogation or lecture to open discussion.

Pipkin's account suggests that we may well have been right in our instinct that first-year placement would help the reception of Legal Profession by emphasizing its centrality, but that we did not go far enough in altering the negative latent messages associated with the course. By keeping the course at two units, when other first-year courses were taught in three-, four-, or five-unit blocks, we made it clear that Legal Profession was, in our view, the least important of those courses. Similarly, by deemphasizing the law of professional ethics, in favor of the theory and sociology of professionalism and the adversary system and the use of simulation role-plays, we marked the course as different and perhaps presumptively less rigorous than traditional courses. More speculatively, one might wonder whether the academic cast of the course did not end up hurting us more with first-year students than it would have with secondor third-year students, precisely because first-year students are so invested in mastering traditional doctrinal and policy analysis. I have often wondered, for example, whether the student who told me that she liked the course readings

22. Because of our efforts at evaluation, the data supporting our move back to the second year was much better than that which supported the initial move to the first year.

23. Despite its somewhat ad hoc and innocent quality, I am proud of our effort. We developed a strong set of teaching materials and a strong cadre of teachers committed to their use. We learned valuable information about legal ethics teaching, including that we could teach a viable and increasingly effective course in the first year. As a result of our experiment, we reestablished the course in the second year, allocated more units to it, and eliminated the resistant, angry third-year students who made the former professional responsibility course pedagogically and personally difficult. I believe we made the right decision at each turn, given the fundamental constraint that the faculty was unwilling to consider further reform of the first-year curriculum.

24. Pipkin, supra note 20 , at 247. 
because they "reminded her of being an undergraduate" intended the remark in a wholly complimentary spirit.

This analysis has two implications, one less cheering and the other more so. The less cheering implication is that certain types of required professional ethics courses-specifically, those that contain a heavy admixture of theory and empirical evidence-may not be viable even at relatively "academic" law schools. Indeed, the implication may be that because ethics courses are not well established in the curriculum, such courses may be even less viable than in other, better established fields. Consistent with this hypothesis, the trend in professional ethics education is toward teaching materials that stress law rather than ethics and the external rather than internal regulation of lawyers. At one level, one can hardly object to this trend. There is lots of "law of lawyering" that is worth learning. Moreover, careful attention to the considerations which shape that law can go far to illuminate how a lawyer ought to act when the legal rules governing her conduct cease to provide clear guidance or, perhaps more radically, when those rules seem clearly unjust. ${ }^{25}$ It is also difficult to criticize reforms that enhance student willingness to engage with legal ethics, and, over time, the willingness of law teachers to do so as well. On the other hand, if there is any area where lawyers ought to have a more empirically grounded, theoretically sophisticated understanding of what is at stake, it is legal ethics, for two reasons. First, as legislators and leaders of the organized profession, lawyers largely design the relevant rules. Second, lawyers are the people who must abide by those rules and accept moral responsibility for actions taken pursuant to them. On this view, the broader acceptance of "law of lawyering" ethics education will not be without real costs.

The second, perhaps more encouraging, implication is that our brief experiment at Boalt Hall does not yield firm general conclusions about the value of a required first-year course or even about the value of the sort of firstyear course that we ran. To do so, in my judgment, we would at a minimum have had to offer a three-unit course in a revised and more spacious second semester, allowing adequate treatment and impressing on students the seriousness of the enterprise. Arguably, we also would have had to try the course in the first semester, the prime time both for catching students at their most receptive and the best possible way to demonstrate the course's importance and conceptual centrality. And certainly we would have had to give the course more time to become a familiar feature of the first-year landscape. It suffered from being the new or "extra" course in the first year, an effect that would have dissipated over time.

Was our faculty wrong, then, to resist giving up three units of the first-year to Legal Profession? Had the issue been raised, would they have been wrong to oppose a three- or four-unit legal profession course in the first semester? A

25. For examples of works suggesting the possibility of an individual professional ethic based on the reasons underlying the rules of professional responsibility, see note 30 , infra. 
full canvass of these issues would take us far afield, into the design of the firstyear curriculum and hotly contested questions like the "right" number of units allocated to beginning Contracts, Torts, and Civil Procedure. Before one reaches those issues, one has to have a theory of the role of the first-year courses and of how legal ethics education fits with that theory. Certainly there is a very plausible account of legal education in which an introductory course in professional ethics is more central to the law school curriculum than any other present first-year courses. It runs as follows.

Suppose we started with the lay public's view, which sees the central problem with lawyers not as lack of competence, but as a lack of ethical standards. On this account, the law and ethics of lawyering ${ }^{26}$ lies at the core of professional education, so much so that leaving the subject until later would make the first-year curriculum profoundly misleading, both ethically and substantively. By focusing exclusively on learning the "law" and the tropes of argument and interpretation that lawyers use to serve their clients, the standard first-year curriculum falsely implies that the only important ethical issues are those of competent performance within a well-functioning attorney-client relationship and a well-functioning adversary system. This renders invisible virtually all the difficult and important issues of professional obligation and system design, and gives students a highly distorted - and potentially dangerous-picture of their future professional role. Is it any wonder that after this introduction, many students wonder about the relevance of professional ethics instruction?

But even if competent practice were the sole aim of first-year instruction, the omission of ethics issues would be hard to defend. I would argue that a lawyer cannot accurately grasp the contours, significance, or potential for reform of U.S. law without understanding the core material of legal ethics. That material includes, at a minimum, the role of lawyers in making, shaping compliance with, and enforcing the law, this country's increasingly controversial attachment to the adversary system, and the circumstances under which actors have access to legal counsel or advocacy. A legal ethics course is also the natural setting to discuss the policy preferences that underly our nation's perennial (and presently heated) national debates about regulation, litigation, and the role of lawyers. Those include our continuing national preferences for weak, poorly funded, and highly politicized governmental and judicial authorities, for litigated, rather than consensual, solutions to problems of governance, and for political and legal processes dominated by private parties and their lawyers. ${ }^{27}$ Finally, the legal ethics course offers students a chance to consider potentially important modes of legal regulation-such as selection on the basis of personal character,

26. I borrow here from the title of Geoffrey Hazard, Susan Koniak and Roger Cramton's excellent book. GeOFfrey HaZard et al., THE Law and ETHICS OF LaWYering (2d ed. 1994).

27. See, e.g., Mirjan R. Damaska, The Faces of Justice and STATE Authority: A COMPARATIVE APPROACH TO THE LEGAL PROCESS (1986); Robert A. Kagan, Adversarial Legalism and American Government, 10 J. POL'Y ANALYSIS \& MGMT. 369 (1991). 
professional socialization, reputation, and professional discipline - that they will not encounter elsewhere in the curriculum. ${ }^{28}$

With all that said, however, one might still doubt that first-year placement is ideal. As our brief experiment at Boalt Hall taught us, there is clearly a sense in which Legal Profession is an advanced course. Its full development is parasitic on students' basic familiarity with critical concepts of legal obligation and procedural regularity and on their emerging awareness, based on exposure to law office work in clinical, part-time, or summer employment, of the practical significance of professional ethics and ethical decisionmaking.

This concern might argue for later placement of the course. Or it might point in the direction of the pervasive approach, which permits basic ethical and institutional concepts to be introduced in traditional first-year courses, and then developed and elaborated in advanced courses. In advanced elective courses, such an approach also has the potential advantage of enlisting the student's enthusiasm for the underlying subject matter in support of the study of the related ethical questions.

While these attractions are real, the pervasive approach suffers from two crippling drawbacks. First, by giving the pieces of legal ethics a home everywhere, it effectively deprives its core concepts of a home anywhere. Without a required course with significant content, there is no place in which students and instructors confront, in any probing or systematic way, the central ethical concepts, institutional and political understandings, and regulatory alternatives that underlie all areas of professional ethics and regulation. ${ }^{29}$ Put more bluntly, without a required course, pervasive ethics is in danger of becoming parochial ethics: It does not provide the kind of centered, comprehensive understanding of the lawyer's role that is the foundation of reflective professional practice. ${ }^{30}$ Moreover, the brief courses that serve as introductions to the pervasive ethics curriculum-often only a few hours, seldom more than a week-do not appear to satisfy the basic conditions of duration and intensity

28. Of course, much of first-year legal education is skills education, notably in the reading of cases and, to a lesser extent, statutes. The legal profession curriculum has a lot of material that is well suited to this sort of skills instruction. Many relevant doctrines, such as agency and fiduciary obligation, involve common law concepts, while the professional rules provide rich opportunities for statutory interpretation.

29. For example, I visited at Stanford this fall and found myself playing a not insubstantial role in the first-year introduction to Stanford's pervasive ethics program. That program involves about 60 pages of assigned reading, a movie, and a total of five hours of class discussion and lecture. Students prepared a single, brief, ungraded written assignment based on that work. Given the other demands of their scheduled, graded first-semester classes and of the legal writing course, I do not doubt that a more intensive introduction would overburden students. On the other hand, I wonder whether such a brief exposure to fundamental ethical issues, under such inauspicious conditions, provides an adequate foundation for developing the issues in other courses or for reflective professional practice.

30. Indeed, it seems to me that the most illuminating insights into the lawyer's legal and ethical obligations, of the kind reflected in the best academic studies, can scarcely be developed or appreciated outside the context of a course which takes a comprehensive view of the subject. See, e.g., Fuller \& Randall, supra note 11; Deborah L. Rhode, Ethical Perspectives on Legal Practice, 37 STAN. L. REV. 589 (1985); William H. Simon, Ethical Discretion in Lawyering, 101 HARV. L. REV. 1083 (1987); David B. Wilkins, Who Should Regulate Lawyers, 105 HARV. L. REV. 799, 801 (1992). 
that researchers have identified as essential for ethics education to "take" in a way that produces lasting differences in ethical orientation. ${ }^{31}$

The second problem with pervasive ethics is suggested by Pipkin's law of latent curricular messages. ${ }^{32}$ It seems, inevitable that by treating ethics in a manner different from, say, contracts or torts, the pervasive curriculum runs a large risk of conveying the message that ethics education is not nearly as important as courses in the other subjects, and hence a risk of engendering resistance or disengagement on a massive scale. It may be that the pervasive method conveys that message so powerfully that no degree of pedagogical dedication can overcome it. At a minimum, Pipkin's analysis suggests that pervasive ethics education cannot succeed without an unusually strong pedagogical commitment from instructors in substantive courses. But the evidence from schools where the pervasive method has been attempted suggests that the opposite is true: Most instructors in substantive courses convey the distinct impression that ethics is an add on.

Given the attendant risks and benefits of each of the options, the ideal solution might well be some combination of a required first-year course and pervasive instruction in the second and third years. Indeed, such a model is implied in our school's Keck Foundation grant program of first-year materials followed by advanced modules in other courses. Many readers are undoubtedly inclined to reject this idea as either utopian or wasteful of scarce resources that ought to be directed elsewhere. Before doing so, they would do well to note that such a system is already in effect for courses like Contracts, Property, and Civil Procedure. Having made these courses the foundations of first-year legal education, we replay and elaborate upon their central structures and concepts in second- and third-year classes. In fact, most of our advanced curriculum relies on and refers repeatedly to that earlier instruction. Neither teacher nor student regards the additional attention to those concepts as excessive, in part because they are understood to be fundamentally important and in part because it is necessary to recall them in order to understand more advanced concepts.

Measured against this utopian standard, I view the outcome of our experiment as an incremental step in the right direction. We learned a powerful lesson-lowering student resistance to the legal profession course in the first year, or anywhere else, depends on making the course a full-fledged and equal part of the curriculum. Since we could not accomplish that in the first year, the faculty has established the core course in a place where we can devote adequate attention (and expanded faculty resources) to it while avoiding the worst problems of third-year cynicism and burnout. Along the way, our extensive collaboration on the materials for the course has developed a cadre of faculty

31. For example, Professor Rest's review of a host of studies seeking to measure the effect of ethics education on ethical judgment found that courses of short duration have no impact on ethical judgment. The strongest effects are found for courses of four to twelve weeks duration. JAMES R. REST ET AL., Moral Development: AdVANCES IN ResearCH AND TheORy 59 (1986).

32. See Pipkin, supra note 20. 
with substantive and pedagogical expertise, who will be available to staff the basic course in the future and who, we hope with some confidence, will bring to their instruction in other courses a sensitivity to professional issues that over time may lead to a more pervasive education that builds on a solid foundation established early in law students' academic careers. 
